\author{
NUMERICAL SOLUTION OF NONLINEAR \\ FIN PROBLEMS VIA INITIAL VALUE METHOD
}

\author{
A. Aziz \\ Department of Mechanical Engineering \\ College of Engineering \\ Riyadh, Saudi Arabia \\ T.Y. Na \\ Department of Mechanical Engineering \\ University of Michigan-Dearborn \\ Dearborn, Michigan 48128
}

(Commmicated by J.P. Hartnett and W.J. Minkowycz)

\title{
Introduction
}

In general the mathematical model for steady, one-dimensional conduction in fins appears as a nonlinear, two-point boundaryvalue problem. The nonlinearities arise due to radiative surface heat transfer, temperature dependent thermal conductivity or heat transfer coefficient etc. [1]. Often in such cases a numerical solution has to be obtained. Examining the literature reporting such solutions it appears that the most commonly used numerical scheme is based on a standard shooting technique in which a succession of guessed values of the missing initial derivative are used until the solution which satisfies the specified boundary condition at the other end is obtained. The disadvantages of this iterative process are long computing time, sensitivity of the solution to guessed initial condition and occasional lack of convergence. With the development of method of transformation groups, it has been possible, in some problems, to overcome these difficulties. The method transforms a boundary value problem into an initial value problem which can then be integrated in one 
sweep without iteration. The present paper demonstrates that this efficient, noniterative scheme can indeed be applied successfully to fin problems. A detailed description of the method and its application to other engineering boundary value problems appear in a very recent book by Na[2].

To demonstrate the applicability of the method, a general boundary value problem is formulated for one-dimensional conduction in a straight fin of uniform thickness. The model allows for temperature-dependent thermal conductivity and for simultaneous convection and power-law radiation both from the faces and the tip. Using a linear transformation the problem is reduced to an initial value problem which can be subsequently integrated numerically in one sweep. Sample numerical results are presented for three special cases: (i) a purely radiating fin with temperature dependent thermal conductivity (ii) convectingradiating fin with constant thermal conductivity (iii) a horizontal fin heated due to laminar film condensation on its surfaces (temperature dependent heat transfer coefficient). These results match very closely with those obtained via the conventional shooting technique.

\section{Fin Boundary Value Problem}

Consider a straight fin of length $L$ and thickness $w$ at constant base temperature $\mathrm{T}_{\mathrm{b}}$. Let the perimeter and cross-sectional area be $P$ and $A$ respectively. The fin is assumed to lose heat by convection to an environment at temperature $\mathrm{T}_{\mathrm{a}}$ with heat transfer coefficient $h$ for the top and bottom surfaces and $h e$ for the tip. Additionally, allowance is made for power-law type radiation from both the surfaces and the tip to a sink at temperature $\mathrm{T}_{\mathrm{s}}$. The surface emissivity for radiation is denoted by $\mathrm{E}_{\mathrm{g}}$. The general form of the power-law term encompasses the cases of (i) constant-property radiating fin, (ii) radiating fin with thermal conductivity and emissivity varying as powers of temperature [3], (iii) convecting fin with temperature-dependent heat transfer coefficient, a situation which arises when the fin is cooled by natural convection, film boiling or nucleate boiling [4] or heated by laminar condensation on its surfaces [5]. Since the 
effect of temperature dependent emissivity is much smaller compared to that of thermal conductivity [6], only the latter is assumed to vary with temperature. A linear variation of the form

$$
k=k_{r}\left[1+B\left(T-T_{r}\right)\right]
$$

is assumed. Based on the foregoing the boundary value problem governing the fin temperature distribution can be written as

$$
\begin{aligned}
& \frac{d}{d x}\left\{\left[1+v\left(\theta-\theta_{r}\right)\right] \frac{d \theta}{d x}\right\}-N_{1}\left(\theta-\theta_{a}\right) \\
& -N_{2}\left(\theta^{m}-\theta_{s}^{m}\right)=0 \\
& x=0, \quad \theta=1, \quad x=1, \quad \frac{d \theta}{d x}=-\frac{H_{1}\left(\theta-\theta_{a}\right)+H_{2}\left(\theta^{m}-\theta_{s}^{m}\right)}{1+v\left(\theta-\theta_{r}\right)}
\end{aligned}
$$

where $\theta=\mathrm{T} / \mathrm{T}_{\mathrm{b}}, \mathrm{x}=\mathrm{x} / \mathrm{L}, \quad \mathrm{N}_{1}=\mathrm{hPL} \mathrm{L}^{2} / \mathrm{k}_{\mathrm{r}} \mathrm{A}$,

$\mathrm{N}_{2}=\mathrm{E}_{\mathrm{g}} \sigma \mathrm{T}_{\mathrm{b}}^{\mathrm{m}-1} \mathrm{PL}^{2} / \mathrm{k}_{\mathrm{r}} \mathrm{A}, \quad v=\beta \mathrm{T}_{\mathrm{b}^{\prime}} \quad \mathrm{H}_{1}=\mathrm{h}_{\mathrm{e}} \mathrm{L} / \mathrm{k}_{\mathrm{r}}$

and $\mathrm{H}_{2}=\mathrm{E}_{\mathrm{g}} \sigma \mathrm{T}_{\mathrm{b}}^{\mathrm{m}-1} \mathrm{~L} / \mathrm{k}_{\mathrm{r}}$.

\section{Solution Method}

To reduce equations $(2,3)$ to an initial value problem, we introduce the linear transformation

$$
x=c^{\alpha} 1 \bar{x}, \quad \theta=c^{\alpha} \bar{\theta}
$$

where $-C$ is taken as the missing initial derivative i.e.

$c=-\left.\frac{d \theta}{d x}\right|_{x=0}$ and $\alpha_{1}, \alpha_{2}$ are constants to be determined. Substituting (4) into $(2,3)$ the transformed equations remain independent of $C$ provided

$$
\alpha_{1}=-1, \quad \alpha_{2}=0, \quad \overline{\mathrm{N}}_{1}=\mathrm{N}_{1} / \mathrm{C}^{2}, \overline{\mathrm{N}}_{2}=\mathrm{N}_{2} / \mathrm{C}^{2}
$$


Since $\mathrm{N}_{1}=\overline{\mathrm{N}}_{1} \mathrm{C}^{2}$ and $\mathrm{N}_{2}=\overline{\mathrm{N}}_{2} \mathrm{c}^{2}$ it is observed that $\mathrm{N}_{1} / \mathrm{N}_{2}=$ $\overline{\mathrm{N}}_{1} / \overline{\mathrm{N}}_{2}$, which means this combination of physical parameters is invariant under the transformation. As suggested in $[2,7]$ we put

$$
\frac{\mathrm{N}_{1}}{\mathrm{~N}_{2}}=\frac{\overline{\mathrm{N}}_{1}}{\overline{\mathrm{N}}_{2}}=\mathrm{n}
$$

The transformed equations now appear as

$$
\begin{aligned}
& \frac{d}{d \bar{x}}\left\{\left[1+v\left(\bar{\theta}-\theta_{r}\right)\right] \frac{d \bar{\theta}}{d \bar{x}}\right\}-\bar{N}_{2}\left[n\left(\bar{\theta}-\theta_{a}\right)+\left(\bar{\theta}^{m}-\theta_{s}^{m}\right)\right]=0 \\
& \bar{x}=0, \quad \bar{\theta}=1, \quad \bar{x}=0, \quad \frac{d \bar{\theta}}{d \bar{x}}=-1
\end{aligned}
$$

Equations $(7,8)$ are to be integrated until the condition

$$
\frac{d \bar{\theta}}{d \bar{x}}=-\frac{H_{1}\left(\bar{\theta}-\theta_{a}\right)+H_{2}\left(\bar{\theta}^{m}-\theta_{s}^{m}\right)}{\bar{x}\left[1+v\left(\bar{\theta}-\theta_{r}\right)\right]}
$$

is satisfied at a certain $\bar{x}$. This value of $\bar{x}$ equals $C$ in accordance with (4). The solution procedure is as follows:

(1) Assign values for $\mathrm{n}, \nu, \mathrm{H}_{1}, \mathrm{H}_{2}, \theta_{\mathrm{a}}, \theta_{\mathrm{s}}$ and $\mathrm{m}$ depending upon the problem.

(2) Assign a range of values to $\overline{\mathrm{N}}_{2}$ and integrate (7) subject to (8) until (9) is satisfied. The value of $\bar{x}$ at this point equals $C$.

(3) Obtain the corresponding values of $\mathrm{N}_{2}$ and $\mathrm{N}_{1}$ from

$$
\mathrm{N}_{2}=\overline{\mathrm{N}}_{2} \mathrm{C}^{2} \text { and } \mathrm{N}_{1}=\mathrm{n} \mathrm{N}_{2}
$$

\section{Sample Results}

To illustrate the computational scheme, results are presented for three special cases. 
Case I: Purely radiating fin with temperature dependent thermal conductivity

For this case, $\mathrm{N}_{1}=0, \mathrm{~m}=4$. Further assume $\theta_{r}=\theta_{s}=0$ and insulated fin tip i.e. $\mathrm{H}_{1}=\mathrm{H}_{2}=0$. Equations $(7,8)$ reduce to

$$
\begin{aligned}
& \frac{d}{d \bar{x}}\left[(1+v \bar{\theta}) \frac{d \bar{\theta}}{d \bar{x}}\right]-\bar{N}_{2} \bar{\theta}^{4}=0 \\
& \bar{x}=0, \quad \bar{\theta}=1 ; \quad \overline{\mathrm{x}}=0, \quad \frac{d \bar{\theta}}{d \bar{x}}=-1
\end{aligned}
$$

The integration of equations $(10,11)$ is carried out until $\frac{d \bar{\theta}}{d \bar{x}}=0$ where $\overline{\mathrm{X}}=\mathrm{C}$. For numerical computation the values of $\nu$ chosen are $-0.5,0$ and +0.5 . For each $\nu$, a set of values of $\overline{\mathrm{N}}_{2}$ are chosen and integration carried out to obtain the corresponding set of values of $c$. The values of $\mathrm{N}_{2}$ follow from $\mathrm{N}_{2}=\overline{\mathrm{N}}_{2} \mathrm{c}^{2}$. The fin efficiency $\eta$ is related to $c$ as follows

$$
n=\frac{(1+\nu) C}{N_{2}}
$$

For brevity, results for temperature distributions are omitted and only the values of $C$ and corresponding values of $\eta$ are presented in Table 1 . To check the accuracy, values of $C$ and $\mathrm{N}_{2}$ were used to integrate the original untransformed equation and the insulated tip condition was always found to be satisfied within $10^{-5}$. As seen in Table 1 the values of $\mathrm{N}_{2}$ are not systematically spaced but this is not a serious drawback because one can readily interpolate either graphically or numerically. The question of choosing the range of $\overline{\mathrm{N}}_{2}$ to cover the desired range of $\mathrm{N}_{2}$ is easily resolved with a few trials.

\section{Case II: Convecting-radiating fin with}

constant thermal conductivity

For this case, $\nu=0, m=4$. Assume $\theta_{r}=\theta_{a}=\theta_{s}=0$ and insulated fin tip i.e. $H_{1}=H_{2}=0$. Equations $(7,8)$ become

$$
\frac{\mathrm{d}^{2} \bar{\theta}}{d \mathrm{x}^{2}}-\overline{\mathrm{N}}_{2}\left(\mathrm{n} \bar{\theta}+\bar{\theta}^{4}\right)=0
$$




$$
\bar{x}=0, \quad \bar{\theta}=1 ; \quad x=0, \quad \frac{d \bar{\theta}}{d \bar{x}}=-1
$$

Following the procedure outlined for case I equations $(13,14)$ are integrated numerically until $\frac{d \bar{\theta}}{d \bar{x}}=0$ where $\bar{x}=c$. Results of calculations for $\mathrm{n}=0.1,0.5$ and 1.0 are given in Table 2 . In this case $n$ is related to $C$ as follows

$$
\eta=\frac{C}{(I+n) N_{2}}
$$

Remarks made earlier regarding the check on accuracy, the uneven spacing of $\mathrm{N}_{2}$ values and the choice of range of $\overline{\mathrm{N}}_{2}$, also apply here.

\section{Case III: Horizontal fin heated by} laminar condensation

Lienhard and Dhir [5] have shown that a fin can be effective in supporting condensation. For a horizontal, the average heat transfer coefficient is of the form

$$
\mathrm{h}=\mathrm{n}\left(\mathrm{T}_{\text {sat }}-\mathrm{T}\right)^{-0.25}
$$

where $\mathrm{T}_{\text {sat }}$ is the saturated condensate temperature and $\mathrm{n}$ is a constant which can be determined using Nusselt-Rohsenow theory [5]. By putting $v=\mathrm{N}_{1}=\mathrm{H}_{1}=\mathrm{H}_{2}=\theta_{\mathrm{s}}=0, \mathrm{~N}_{2}=\mathrm{E}, \mathrm{m}=\frac{3}{4}$, equations $(2,3)$ reduce to the form given in [5]. The parameters $\theta$ and $E$ follow their definitions in [5]. The transformed equations become

$$
\begin{aligned}
& \frac{\mathrm{d}^{2} \bar{\theta}}{d \overline{\mathrm{x}}^{2}}-\overline{\mathrm{E}} \bar{\theta}^{-3 / 4}=0 \\
& \overline{\mathrm{x}}=0, \bar{\theta}=1, \quad \overline{\mathrm{x}}=0, \quad \frac{\mathrm{d} \bar{\theta}}{\mathrm{d} \overline{\mathrm{x}}}=-1
\end{aligned}
$$

As before equations $(17,18)$ are integrated numerically until $\frac{d \bar{\theta}}{d \bar{x}}=0$ where $\bar{x}=c$. The value of $E$ follow from $E=\bar{E} c^{2}$. In this case $n$ is related to $c$ as follows

$$
\eta=c / E
$$


Table 3 records the values of $C$ and $n$ for a range of values of E. A plot of $\eta$ versus $E$ from present data virtually coincides with the plot in [5] which is based on shooting type numerical solutions.

\section{Concluding Remarks}

With the use of transformation groups, a large class of nonlinear fin boundary value problems can be reduced to initial value problems and subsequently integrated without iteration. Since the method dispenses with the guess work associated with the shooting technique, it is computationally more efficient.

\section{References}

1. D.Q. Qern and A.D. Kraus, Extended Surface Heat Transfer, McGraw Hill, New York, 1972 .

2. T.Y. Na, Computational Methods in Engineering Boundary Value Problems, Chapter 9, Academic Press, New York, 1979.

3. A. Campo and H.S. Wolko, J. Spacecraft, 10, 811 (1973).

4. K.W. Haley and J.W. Westwater, Proceedings Third International Heat Transfer Conference, $\underline{3}, 245$ (1966).

5. J.H. Lienhard and V.K. Dhir, J. Heat Transfer, 96, 197 (1974).

6. N.0. Stockman and J.L. Kramer, NASA Technical Note D-1878.

7. T.C. Scott, G.L. Rinschler and T.Y. Na, J. Basic Engineering, 94, 250 (1972). 
TABLE 1

Values of $C$ and $n$ for Case $I$

\begin{tabular}{|c|c|c|c|c|}
\hline$v$ & $\overline{\mathrm{N}}_{2}$ & C & $\mathrm{N}_{2}$ & $\eta$ \\
\hline+0.5 & $\begin{array}{l}9.0 \\
8.5 \\
8.0 \\
7.5 \\
7.0 \\
6.5 \\
6.0 \\
5.5 \\
5.0 \\
4.5\end{array}$ & $\begin{array}{l}0.2199 \\
0.2400 \\
0.2599 \\
0.2797 \\
0.3200 \\
0.3599 \\
0.4098 \\
0.4898 \\
0.6199 \\
0.8700\end{array}$ & $\begin{array}{l}0.4353 \\
0.4896 \\
0.5405 \\
0.5868 \\
0.7166 \\
0.8420 \\
1.0076 \\
1.3196 \\
1.9215 \\
3.4057\end{array}$ & $\begin{array}{l}0.7577 \\
0.7353 \\
0.7212 \\
0.7150 \\
0.6698 \\
0.6411 \\
0.6100 \\
0.5567 \\
0.4839 \\
0.3832\end{array}$ \\
\hline 0 & $\begin{array}{l}4.7 \\
4.5 \\
4.3 \\
4.1 \\
3.9 \\
3.7 \\
3.5 \\
3.3 \\
3.1 \\
2.9 \\
2.7\end{array}$ & $\begin{array}{l}0.3099 \\
0.3298 \\
0.3600 \\
0.3899 \\
0.4198 \\
0.4699 \\
0.5299 \\
0.6100 \\
0.7099 \\
0.8900 \\
1.2300\end{array}$ & $\begin{array}{l}0.4514 \\
0.4896 \\
0.5571 \\
0.6234 \\
0.6873 \\
0.8170 \\
0.9829 \\
1.2279 \\
1.5623 \\
2.2971 \\
4.0847\end{array}$ & $\begin{array}{l}0.6865 \\
0.6736 \\
0.6462 \\
0.6254 \\
0.6108 \\
0.5751 \\
0.5391 \\
0.4968 \\
0.4544 \\
0.3874 \\
0.3011\end{array}$ \\
\hline-0.5 & $\begin{array}{l}1.65 \\
1.60 \\
1.55 \\
1.50 \\
1.45 \\
1.40 \\
1.35 \\
1.30 \\
1.25 \\
1.20 \\
1.15\end{array}$ & $\begin{array}{l}0.5500 \\
0.5799 \\
0.6199 \\
0.6700 \\
0.7300 \\
0.7899 \\
0.8800 \\
0.9900 \\
1.1300 \\
1.3500 \\
1.7000\end{array}$ & $\begin{array}{l}0.4991 \\
0.5381 \\
0.5957 \\
0.6733 \\
0.7727 \\
0.8736 \\
1.0454 \\
1.2741 \\
1.5960 \\
2.1870 \\
3.3235\end{array}$ & $\begin{array}{l}0.5500 \\
0.5388 \\
0.5203 \\
0.4975 \\
0.4724 \\
0.4521 \\
0.4209 \\
0.3885 \\
0.3540 \\
0.3086 \\
0.2557\end{array}$ \\
\hline
\end{tabular}


TABLE 2

Values of $c$ and $n$ for Case II

n

$\overline{\mathrm{N}}_{2}$

C

$\mathrm{N}_{2}$

$n$

$\begin{array}{rllll}0.1 & 6.75 & 0.1598 & 0.1723 & 0.8431 \\ 6.25 & 0.1800 & 0.2025 & 0.8081 \\ 5.75 & 0.2000 & 0.2300 & 0.7905 \\ 5.25 & 0.2198 & 0.2535 & 0.7882 \\ 4.75 & 0.2497 & 0.2961 & 0.7666 \\ 4.25 & 0.2999 & 0.3822 & 0.7133 \\ 3.75 & 0.3598 & 0.4854 & 0.6738 \\ 3.25 & 0.4700 & 0.7179 & 0.5952 \\ 2.75 & 0.6599 & 1.1976 & 0.5009 \\ 2.25 & 1.2700 & 3.6290 & 0.3181\end{array}$

0.5

$4.8 \quad 0.1599$

4.4

0.1695

0.1227

0.1264

0.1599

0.1736

3.6

0.1999

0.2159

0.2597

0.3097

0.2686

0.3647

0.3898

0.5618

1.0238

0.7999

1. 9200

4. 4237

0.8688

0.8940

0.8334

0.8433

0.8019

0.7686

0.7125

0.6289

0.5209

0.2893

1.0

$\begin{array}{ll}2.6 & 0.2300 \\ 2.4 & 0.2498 \\ 2.2 & 0.2799 \\ 2.0 & 0.3097 \\ 1.8 & 0.3598 \\ 1.6 & 0.4299 \\ 1.4 & 0.5199 \\ 1.2 & 0.6699 \\ 1.0 & 0.9399 \\ 0.8 & 1.6699\end{array}$

0.1375

0.1498

0.8364

0.1723

0.1918

0.8338

0.8122

0.8073

0.2330

0.7721

0.2958

0.7267

0.3784

0.6870

0.5386

0.6219

0.8835

0.5319

0.3743 
TABLE 3

Values of $C$ and $n$ for Case III

$\bar{E}$

1.0000

0.9500

0.9000

0.8900

0.8800

0.8790

0.8780

0.8770

0.8760

0.8759

0.8758

0.8757

0.8756
C

1.6499

1.8999

2.3999

2.6200

3.0600

3. 1500

3.2700

3.4400

3.8200

3.8900

4.0000

4.1600

4.6700
E

2.7221

3.4290

5.1835

6.1093

8.2400

8.7219

9.3884

10.3781

12.7829

13.2542

14.0128

15.1545

19.0959
0.6061

0.5540

0.4630

0.4288

0.3714

0.3612

0.3483

0.3315

0.2988

0.2935

0.2854

0.2745

0.2445 